\title{
Using Total Quality Management Model to Face the Economic Crisis: The Case of Mercadona
}

\author{
Miguel Blanco Callejo \\ Universidad Rey Juan Carlos \\ Spain
}

\section{Introduction}

The aim of this chapter is to describe the recent evolution of Mercadona, a leading Spanish family-owned supermarket company, that has become a worldwide benchmark in retailing industry (Blanco and Gutierrez, 2010; Ton and Harrow, 2010). The chapter presents the company and describes the 1993's top management decision of implement Total Quality Management (TQM) as well as the outstanding and rapid growth of the firm between 1995 and 2008 under that management model (Blanco and Gutierrez, 2010). The surge of the economic crisis which has its origin in the United States in the summer of 2007 started to affect significantly Spain in the second half of 2008. The crisis has had a dramatic impact in the Spanish Economy and Society declining the GDP $-3.9 \%$ in 2009 and rocketing unemployment rate to $21.5 \%$ in October 2011 (INE, 2011). In September 2008 consumer spending dropped off sharply affecting Mercadona's turnover. This situation was a real challenge for the top management team and motivated a significant realignment of the company according to its management model goal: "anticipating and meeting its customers' needs". Anyway, the strength of Total Quality Management has allowed the company to face successfully this situation by refocusing in its management model and adopting innovative and pioneering initiatives in the Spanish retailing industry.

As a supermarket chain providing basic food and hygiene products to its customers Mercadona started to suffer a sustainable client's loss in the second half of 2008. Facing the situation the company has put the customer back at the center of the company's decisions, taking only those steps that provide customer value (Mercadona, 2010; Ton and Harrow, 2010). Given this context Mercadona reviewed all its references, tightened up the product assortment and has launched a campaign to reduce its prices as much as possible "pinching pennies in all its processes" in order to provide the "shopping cart menu" to its customers, offering the highest quality products at the market's most economical prices. Mercadona's recent economic and financial results seem to show the adequacy of the firm's strategy to overcome the economic crisis and to continue firmly with its growth and outstanding development in the upcoming future.

\section{Mercadona}

Mercadona is a Spanish family-owned supermarket company dedicated to the commercial distribution of food and hygiene products. The firm runs large supermarket (averaging 
between 1,300 and 1,500 square meters of retail space) following a model of local city centre stores. The 63,500 employees' company finished 2010 with 1,310 urban supermarkets representing a market share of $13.1 \%$ of the total food store retail space in Spain (Mercadona, 2010). Mercadona's objective is to fully satisfy the grocery, home cleaning, hygiene and pet product needs of its customers and their pets. The company would like to be a "prescriber" that means that Mercadona recommends to its customers the best products. Every one of the supermarkets has an ample and efficient selection that includes up to 8,000 different items which combine Mercadona's brands and other commercial brands highly recognized by the customers. This large selection of products pretends to satisfy necessities of the 4.4 million households that usually place their trust in the company every year (Mercadona, 2010).

The company name Mercadona S.A. (Initial letters from Spanish Sociedad Anónima, publiclimited company), appeared in 1977, but the company actually originated in Cárnicas Roig, a family firm owned by Francisco Roig Ballester specialized in carving and selling meat. The firm subsequently evolved into a chain of eight grocer's shops (Mercadona, 2010). In 1981, one of Francisco's sons, Juan Roig, now running the firm, along with his brother Fernando and sisters Trinidad and Amparo bought Mercadona from his parents. At that time, they had eight stores with some 300 square meters of retail space each. It was a small commercial chain of various stores, which soon began to growth in size, first in the Valencia region and then in other areas of Spain. The firm's expansion was coincident with a period of growth in the commercial distribution sector in Spain, which had various causes, in particular, the increasing concentration of the population within cities and the massive entry of women into the labor market. This growth attracted the attention of the large European distribution chains, which began to enter in the country. The strategy of these large companies was to open major retail outlets (hypermarkets), and offer low prices in particular products accompanied by strong promotions, special offers and discounts that were supported by aggressive advertising campaigns in the media (Navarro, 2005). The firms achieved low prices by putting pressure on their suppliers to cut their prices as far as possible. Customers attracted by the low prices on some products also bought other products not on special offer that yielded high profit margins (Blanco and Gutierrez, 2010).

As a consequence of this strategy, in the 1990s the food distribution sector became highly concentrated and foreign multinationals controlled a large part of the market. The competition from these firms intensified the rivalry in the industry, which was now mature, with strong competition and low margins. In 1990, Juan Roig, along with his wife, Hortensia Herrero took over control of the company. After that, in the early 1990s, Roig faced the first great challenge for the firm. As a consequence of the arrival of the International Retail chains profit margins decreased significantly all through the supermarket industry. Mercadona responded to this highly changeable and turbulent environment by adopting a similar policy to that of the large hypermarket chains. The retailer put downward pressure on its suppliers' prices and ran intensive advertising campaigns to promote its special offers every day. But the results were not as good as expected, since this was the same strategy as the big hypermarket chains'. Mercadona was selling more, but every year its profits declined ${ }^{1}$.

\footnotetext{
${ }^{1}$ In 1990, with a turnover of $€ 763 \mathrm{~m}$, Mercadona's profits were just under $€ 15 \mathrm{~m}$. A year later its turnover rose to $€ 877 \mathrm{~m}$, but its profits fell to under $€ 6 \mathrm{~m}$ (Navarro, 2005).
} 
This was a very tricky time for Mercadona, which had to face some extremely difficult situations. Nevertheless, the President ignored tempting offers to buy the company and stuck firmly to his commitment to remain in the business. Thus, in 1993 Juan Roig decided to implement a strategy that broke radically with the dynamic of the sector: he introduced the TQM model as the basis of all its operations. This involved a strategic switch from the Supermarket industry's traditional high-low pricing with promotions to a new commercial strategy summarized in a simple slogan "Siempre Precios Bajos" (SPB, which translates as "Always Low Prices") and a culture of quality and continuous improvement (Blanco and Gutierrez, 2010; Ton and Harrow, 2010).

While its competitors continued with their massive daily advertising campaigns in the media, Mercadona immediately stopped all its advertising spending. Mercadona cancelled all its special offers, and made a commitment to its customers always to sell at the same price, and to its suppliers to remain loyal to them and maintain stable prices for years (Caparrós and Biot, 2006). This was quite a turnaround, as suppliers had previously seen Mercadona as one of the toughest negotiators. The firm's main objective was to protect itself in the midst of all this turbulence and implement an unusual and original model, novel in the commercial distribution sector: price, supplier and employee stability to achieve permanent customers. The notion was to allow the customers enjoy a Total Shopping with products of the highest quality at the lowest prices on the market keeping the motto "quality doesn't have to be more expensive" (Mercadona, 2010)

The results immediately after adopting the new model were not very promising: although the firm managed to practically double its sales from four years before, its profits were less than half. But the President stuck by his decision and firmly maintained the strategy based

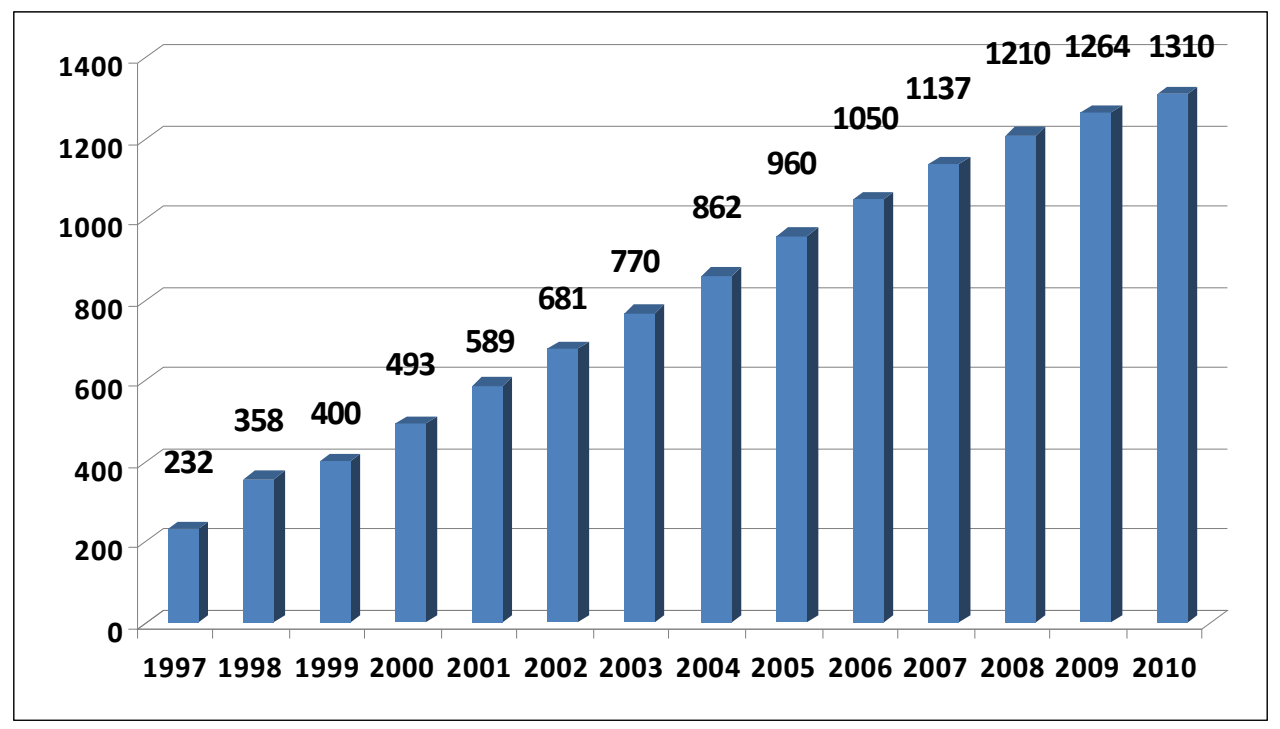

Fig. 1. Evolution of Mercadona's stores

Source: Mercadona's Annual Reports 
on the new management model. In 1995 its performance improved, and Mercadona soon entered a spectacular and unstoppable process of growth, which was mainly organic. From 1995, the focus on TQM worked well for Mercadona and between 1998 and 2008, Mercadona enjoyed double-digit growth in sales and profits. Supermarkets spread out throughout the whole country like an olive-oil spill. By the end of 2008, it was the biggest supermarket chain in Spain, with 1,210 stores and 61,500 employees (Ton and Harrow, 2010). Moreover, in recent years Mercadona has maintained a rate of new supermarket openings of nearly 100 per year (Figure 1). The growth rate in its sales of over 25\% per year from 2000 to 2006 makes Mercadona the $14^{\text {th }}$ fastest-growing retailer in the world, and in 2006 it was the fastest-growing food distributor in the world, after the American commercial distribution giant Wal-Mart, (Deloitte, 2007).

\section{Mercadona's total quality management model}

Mercadona's management firmly believes that adopting and maintaining the TQM model has been critical in allowing the firm to achieve this rate of growth and these spectacular economic results. As Juan Roig, Mercadona's president stated: "Without doubt one of the greatest milestones of Mercadona was the implementation of the Total Quality Model. The involvement of all those whom we train at Mercadona in applying and developing it is doubtlessly the reason for our success" (Ton and Harrow, 2010: 2). Through this approach, management has impressed on the firm a clear orientation to satisfy the needs and expectations of all its stakeholders. On the basis of this approach Mercadona has defined five components in the firm: first, customers ("the Bosses"); second, the employees; third, the suppliers; fourth, society, and fifth, capital. All are equally important, but in that sequential order, (Mercadona, 2010). As the president of Mercadona noted "Mercadona's mission is not just to make a profit, but to make it while satisfying all of the five components" (Ton and Harrow, 2010)

Mercadona's TQM model starts from a universal premise: "to be satisfied, first you have to satisfy everyone else", (Mercadona, 2007). Thus, in the first place, Mercadona orients its entire business model towards the complete satisfaction of its customers, which the firm considers so important that internally it calls them its "bosses". In the same sense, the management is convinced that the workers - who are the people who have to satisfy the customers in the stores - must, in turn, be satisfied as well. This is why the firm, has established its own way of managing its employees, implementing policies that seek to encourage their self-realization through job security and stability, training, internal promotion and improvements in their quality of life. It is the suppliers' products that have to maximally satisfy the firm's customers, so Mercadona has established a relationship with its suppliers based on trust, cooperation, mutual collaboration and stability. Society is the medium in which the firm carries out its activities, so Mercadona feels involved with and ethically committed to its protection and development. Finally, by satisfying the needs of its customers, employees, suppliers, and society, Mercadona contributes to satisfying the expectations of the fifth component of its model, capital (Figure 2).

Despite its apparent simplicity, applying the TQM model is neither simple nor easy. In fact, one of the main difficulties is to introduce and develop programs and tools allowing the firm to satisfy each and every one of its diverse components, and at the same time, ensure that the components perceive that the firm is satisfying their needs so the firm transmits the 
image of a responsible and committed company. In any case, with this powerful model Mercadona has gained competitive advantages over its rivals, has been able to globally orient its strategy and organizational culture and has had adopted a coherent decisionmaking tool. So, any initiative proposed in the company must first be evaluated for its compliance with the model. The firm adopts and implements proposals only when their consequences are satisfactory to all five components, otherwise it rejects them.

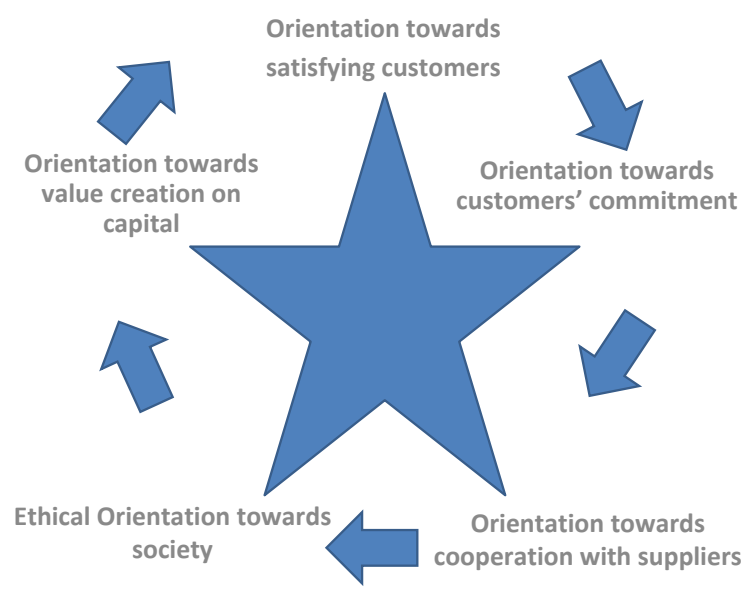

Fig. 2. Mercadona's Total Quality Management Model

Source: Blanco and Gutierrez (2010)

\subsection{Orientation towards bosses' (customers') satisfaction}

One of the fundamental cornerstones of the Total Quality Management Model is its orientation towards satisfying customer needs. This is why Mercadona puts the customer in a privileged position and carries out a large number of activities and initiatives to be able to care for its customers, strengthen their loyalty, and help them generate the maximum possible value from doing their shopping in Mercadona stores.

For Mercadona, the customers are at the center of its activity, since its very survival depends on their decision to shop in Mercadona supermarkets or elsewhere. Nevertheless the staff of Mercadona never spoke about their customers; they spoke of their "Bosses". Thus, the firm calls anyone who shops in its stores "boss". Under this premise, the whole organization is focused on providing an excellent service to its customers. This conception places the customer at the top of the firm's inverted organizational pyramid, and the function of the leader and the rest of the organization is to serve the customer. So, everyone's job is to provide "the Bosses" with the best quality-to-price ratio, the correct assortment of products and the highest level of service while ensuring that the Bosses could complete their purchases as quickly as possible (Ton and Harrow, 2010).

The culture of serving the customer prevailed throughout the business. Given the customer's privileged position, Mercadona's philosophy is to continually increase the "value for the customer" by maintaining its "Always Low Prices" policy and eliminating special offers, promotions and temporary discounts. A key service to "The Bosses" is 
keeping prices not only as low as possible but also as stable as possible (Ton and Harrow, 2010) But the philosophy not only focuses on prices. All the firm's actions are oriented toward satisfying all the customer's specifications, whether known or potential future expectations. In order to find these out, Mercadona maintains a constant and direct dialog with its "bosses", carrying out activities to collect information, opinions and needs from its customers: meetings with neighbors in neighborhoods where new stores are being opened, monographic courses on product lines, open days, blind tests, free customer service hotline, and suggestion boxes in supermarkets ${ }^{2}$. These operations require considerable economic investment from Mercadona, but the firm considers this form of contact more appropriate than big advertising campaigns in the media, which are extremely expensive and collect little information from the customers. Mercadona directly learns about its customers' tastes, the products habitual customers need, and the future trends in different lines of consumption. The firm then tries to anticipate their future needs through innovation, $R \& D$ and product improvement programs.

On the basis of the information collected and distributed, Mercadona carries out actions to increase value for the customers. The aim is to give them the chance to carry out all their shopping under the principles of "maximum quality, maximum range, maximum service, minimum cost and minimum time-always". With regard to quality, the retailer stresses the nutritional quality of its more than 8,000 products $^{3}$. But quality also involves convenience, speed, comprehensiveness of service, and product variety. Product variety - the maximum range-does not mean offering a large number of brands, but rather all the products that satisfy all the customer's needs in food, hygiene, cleaning and pet food. Moreover, Mercadona aims to become a "prescriber": choosing and recommending products for their quality and minimum price. Mercadona guarantees the life and name principles for those products, guaranteeing the origin and date of packaging of the products, as well as the same name on products of the same quality. For this, the firm has designed a relationship system with the suppliers of its own-brand products 4 . This reduces customer insecurity, strengthens customers' loyalty to recommended products, and generates trust. With regard to service quality, Mercadona makes shopping as convenient as possible: payment by credit card, loyalty card, online or telephone shopping, home delivery, and free parking for customers. Moreover, the firm improves the convenience of the store by using a very functional design,

\footnotetext{
${ }^{2}$ In 2006, Mercadona used direct communication in 180,000 encounters. This type of action enabled the firm to directly reach more than $1.9 \mathrm{~m}$ households. The company has 250 employees (monitors) that are collecting information in the supermarkets directly from the clients. In addition to that Mercadona has a customer-service department consisting of more than 90 employees, and the firm responded to 460,000 customer consultations in 2010. Each complaint is perceived as an "opportunity", and the employees are obliged to respond to the customers, Mercadona (2010).

${ }^{3}$ Mercadona's quality department works with its suppliers to guarantee the nutritional quality of all the firm's food products. In recent years, the firm has introduced more fibre-rich foods and green products, substituted saturated fat with sunflower oil, introduced low-salt products, started food traceability programs with its suppliers, and signed collaboration agreements with certification specialists and the Spanish Ministry of Health and Consumer Affairs to encourage healthy consumption habits and improve the population's nutrition, Mercadona (2000-2007).

${ }^{4}$ Mercadona's own brands are Hacendado (food), Bosque Verde (cleaning products), Deliplus (hygiene products), and Compy (pet food). These products are endorsed by both Mercadona and the "intersuppliers", and their quality, traceability and food safety is guaranteed at the lowest possible price (Mercadona, 2010).
} 
what Mercadona calls "Ambience Stores" (Blanco and Gutierrez, 2010). From 2000, the stores are divided into six ambiance store sections (butcher, fish, bakery, fruit and vegetables, cosmetics and deli), each with its own décor and adjusted and designed depending on its marketing requirements. The stores have air-conditioning, shelves are restocked outside opening hours, products come in various packaging formats according to customers' needs, and the firm aims to minimize the time customers spend shopping. The notion behind this is to "provide value to the Bosses' shopping experience". The "Ambience stores" offer Mercadona's customers larger supermarkets with more pleasant atmospheres and a more logical product arrangement (Mercadona, 2010)

The result of this policy was a spectacular growth in the firm's sales: turnover has increased more than nine-fold in the past decade from 1997 to 2007 his growth is not only down to new store openings: the company has also increased its same-store sales considerably increasing it by an annual average of around 8\% between 2005 and 2007 (Figure 3).

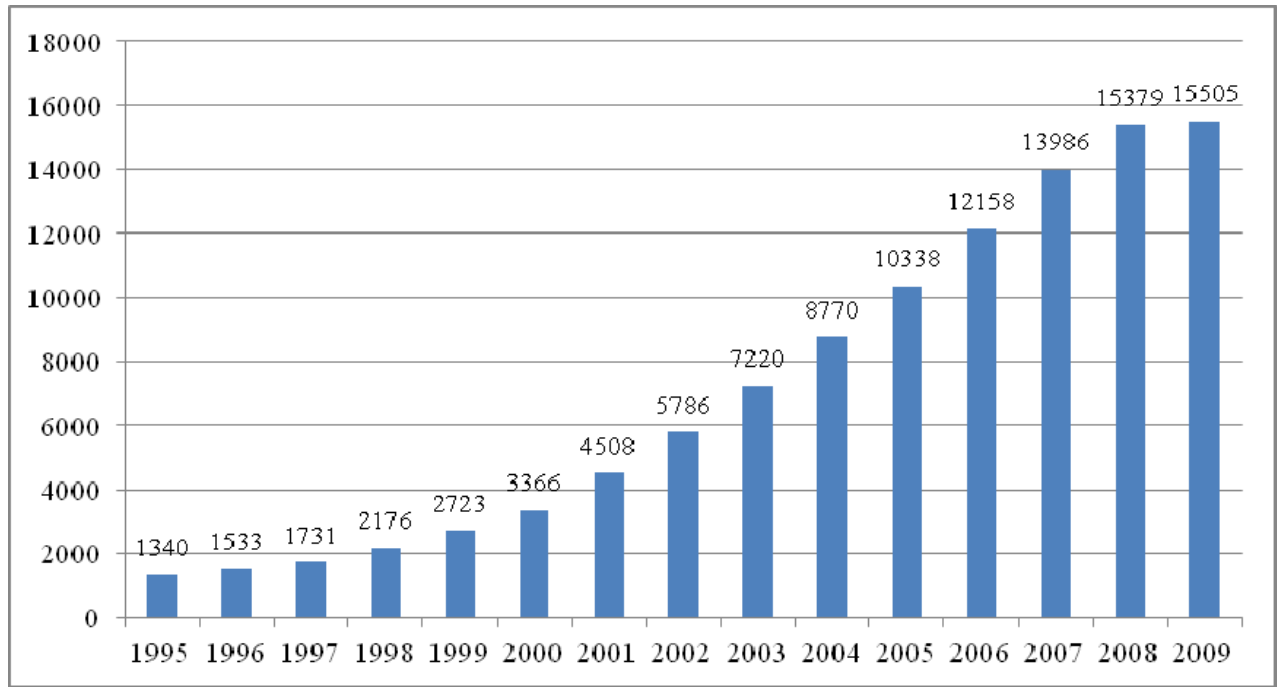

Fig. 3. Evolution Mercadona sales 1995-2009 (€000s)

Source: The Authors, based on Mercadona Annual Reports

\subsection{Orientation towards employee's commitment}

For Mercadona, the orientation toward the employees is another cornerstone of the TQM model. The premise is that quality is made by people, and all 63,500 employees $(67 \%$ women) need to be conscious of quality. The firm needs to achieve the commitment, involvement and/or participation of its workers by incorporating certain values that translate into concrete practices in human resources management. So Mercadona's human resources policy is based on providing its employees with stability, good working conditions, training, transparency, compensation, quality of life and opportunities for advancement (Ton and Harrow, 2010).

Within Mercadona's management, Total Quality is based on the universal premise that "in order to be satisfied, one must first satisfy others". The search for the total satisfaction of 
what Mercadona considers its most valuable asset, its employees is "relentless". To this end, Mercadona's human resource model is based on leadership and relies on self-realization, permanent employment, ongoing training and striking a balance between work and family life for everyone at the company. This makes it possible for the person who has to satisfy "The Boss" to in turn be satisfied (Mercadona, 2010)

With regard to staff selection and recruitment, Mercadona looks for people who fit in a quality environment. Mercadona tried to recruit store employees who would fit its carefully developed and distinctive culture. Candidates must be at least secondary-school graduates, and the selection process involves cultural knowledge and psycho-technical tests, interviews, and group dynamics. Recruiters held meetings at which they interviewed applicants, explained the job conditions, and then placed the applicants into groups where they develop a role-playing scenario. Recruiters received close to 30 applicants per opening and typically interviewed three for each position (Ton and Harrow, 2010)

Employees' training begins as soon as they join the firm with the so-called "Welcome Program". Before they start work, all employees receive 4-weeks, full-time training on the TQM model, which aims to inculcate the firm's culture and cost 5,000€ (Ton and Harrow, 2010). To aid learning the firm gives all its workers manuals outlining the main ideas of the model, plus practical exercises that are subsequently evaluated in exams and written tests. After taking up their posts, the workers receive very varied training during their time in the firm, including courses on how to use new technologies, task specialization in the supermarket, leadership, and occupational safety and health ${ }^{5}$. The training programs are taught by staff members and evaluated internally. Moreover, they often take place in the supermarkets themselves, all of which have specially-designed training rooms. The aim of the training policy is to develop employees' skills, and the policy is accompanied by an internal promotion policy that facilitates employees' identification with Mercadona. In fact, all the firm's senior managers started at the bottom.

Mercadona has designed a simple and complete compensation policy aimed at strengthening its link with its workers and favoring their identification with the project. Part of each employee's compensation is fixed, and the other part is variable, satisfying the equity principle: "for equal responsibility, equal pay". The fixed component has only four bands, and is based on three criteria: experience, responsibility, and performance. The variable component depends on the company and each individual supermarket meeting their objectives. In any case, Mercadona pays wages above the sector average, and the firm consequently demands more commitment from its workers in exchange. The evaluation of the performance and quality that the employee shows in their work, which is carried out by the employee's immediate superior, is determinant in pay rises and promotions. It is significant that the majority of Mercadona's employees earn bonuses for meeting objectives ${ }^{6}$.

On the other hand, jobs are designed broadly, which enhances both the firm's flexibility and the workers' employability. Each worker knows half an hour in advance what their function

\footnotetext{
${ }^{5}$ Training investment amounted to $€ 30 \mathrm{~m}$ in 2010 an average of $471 €$ per employee. The firm fave more than 1,2m hours of training in 2010 (Mercadona, 2010).

${ }^{6}$ Bonuses totalled $€ 25 \mathrm{~m}$ into 2001, €52m in 2002, €64m in 2003, €81m in 2004, and €104m in 2005. In 2006 Mercadona had foreseen a bonus of $€ 124 \mathrm{~m}$, but its net profits of $€ 242 \mathrm{~m}$ meant the firm distributed an extra $€ 43 \mathrm{~m}$. Each worker earned a bonus of between 1,500 and €3,000, Mercadona (2001-2006). In 2010 in the midst of global financial crisis bonuses totalled $€ 210$ (Mercadona, 2010)
} 
will be that day, and this depends on variables such as the number of customers, restocking needs, and staff available in the store. The firm has tried to standardize different types of timetable through its "standard timetable" program. All timetables have the same start and finish times regardless of the day of the week, and staff members have a maximum number of hours work per week. Mercadona workers also have a concentrated working day. In other words, they do not work the split shifts - with a long lunch break from 2 to 5 o'clockthat are typical in Spanish stores. This program also allows workers to know their timetables one month in advance and hence be able to plan their 30 days per year vacations (Mercadona, 2010).

Mercadona also aims to reconcile its employees' working and personal lives as far as possible through stability programs, additional services and benefits, as well as protect its workers to the maximum. In a sector where temporary contracts are the norm, all of Mercadona's staff has stable, indefinite-duration contracts. Moreover, Mercadona continually tries to improve its employees' working conditions. The firm offers free kindergartens in its logistics centers, pays for one month extra maternity leave, does not open its supermarkets on Sundays, and has a policy allowing workers to work in the supermarket closest to their homes. Finally, Mercadona also carries out preventive and corrective activities in the area of occupational safety and health through a culture of internal prevention that measures and actively combats accidents and illnesses. In addition, all the firm's employees have life insurance. Mercadona pays employees $100 \%$ of their wages if they are incapacitated, and the firm has measures in place to help the family if a company worker dies.

With all these actions included in a comprehensive human resources policy and in the framework of its TQM model, Mercadona has managed to considerably reduce its employee

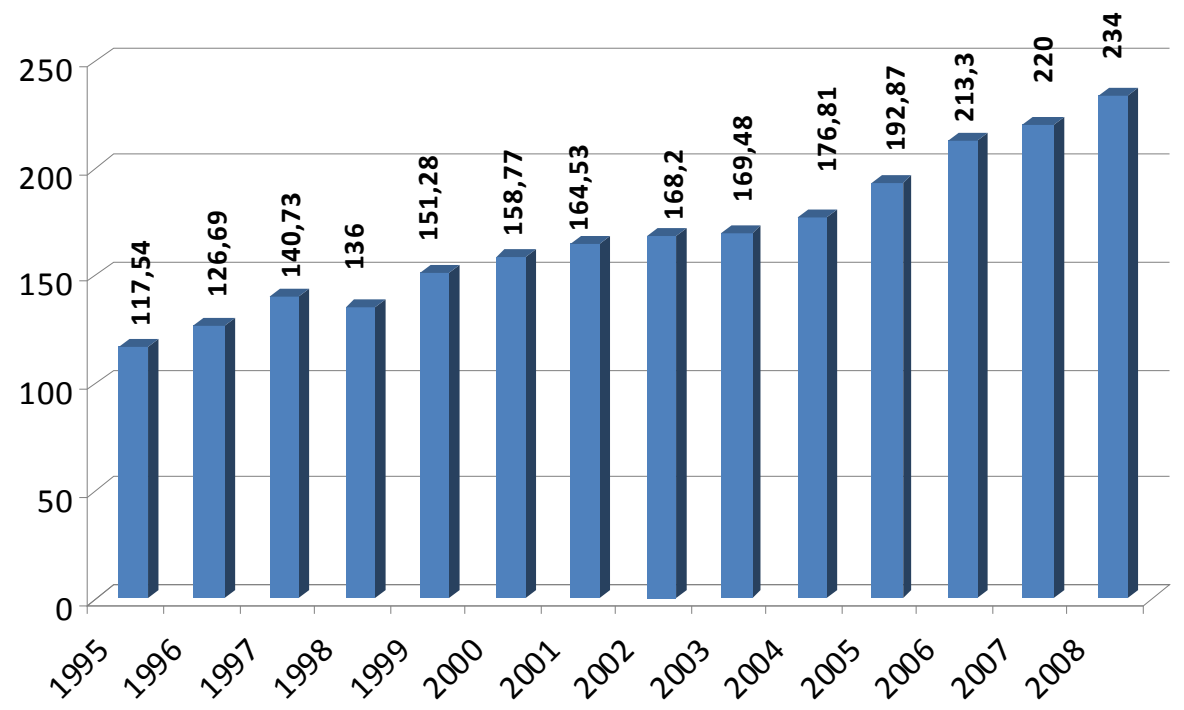

Fig. 4. Evolution Sales/Employees ratio 1995-2008 (€000s)

Source: The Authors, based on Mercadona Annual Reports. 
turnover and absenteeism figures, which are traditionally very high in the sector. At the same time, the firm has also raised its workers' productivity levels considerably, and consequently its own results. The following figure shows the upward trend in sales per employee (Figure 4).

\subsection{Orientation towards cooperation with suppliers}

Incorporating the principle of external cooperation into the TQM value system involves extending cooperation beyond company limits. Mercadona puts this into practice with its suppliers in a special way. Mercadona's relationship with its suppliers seeks cooperation, stability in the relationship, mutual benefits, and the sharing of training and information to improve all the business processes.

The starting point is the adoption of a model of "process management and analysis". Mercadona studies and analyzes these processes from when the products leave the supplier to when they reach the customer. The central idea is that any inefficiency in the production process will eventually reach the end-customer. The aim is to iron out inefficiencies, and to try to extend cooperation to the whole value chain and even reach the suppliers' suppliers.

Mercadona believes that in order to optimize process management it is necessary to generate a relationship of mutual trust with its suppliers. This relationship starts from the premise that the continuity of the supplier-Mercadona relationship is in the hands of the end-customer. The supplier will continue to supply Mercadona if it can respond to and satisfy customer needs. Thus, the supplier becomes a fundamental element for satisfying the customer, and according to Mercadona's philosophy, the supplier must also be satisfied with its relationship with Mercadona, generating synergies between both parties. Mercadona's suppliers share certain generic characteristics: they are partners, capitalists, and focused on adding value for the customer. They are partners because the firm establishes a relationship with Mercadona in which both parties share the objective of fully satisfying the customer. They are capitalists because the supplier risks capital in an attempt to earn profits. And what is most important, the firm must be focused on the customer. It must be able to offer value thanks to its expertise in its area of activity: carrying out $R \& D$ and innovation, and knowing the raw materials, processes and procedures of its particular business.

Given the generic characteristics of its suppliers, Mercadona distinguishes between four categories of supplier: classic, "distressed" suppliers, intermediaries, and what the firm calls "intersuppliers". Mercadona maintains a conventional contractual relationship with "classic suppliers", which supply products and services that the customers demand mainly as a result of these companies' marketing. "Distressed suppliers" are producers that have difficulty finding a market for their products. Mercadona acquires their products, and these firms' very survival depends on their sales in this supermarket chain. Working with Mercadona allows these firms to stay in business, and hence avoid exits that would have traumatic effects on the workforce. Intermediaries are agents operating between the supplier and Mercadona. The retailer believes that these intermediaries do not add value, are unnecessary and only increase the cost of the product to the customer, so it tries to avoid them.

Finally, the so-called "intersuppliers" or "integrated suppliers" (Ton and Harrow, 2010) are Mercadona's fourth category of supplier. Mercadona works with over 2,000 suppliers, of whom approximately 100 were "integrated suppliers" who supplied it home-brand 
products (Mercadona, 2010; Ton and Harrow, 2010). The Integrated Suppliers, manufacturers of Mercadona's brands and with which the company has a long-term mutual cooperation and commitment relationship regulated by way of a Sound Business Practices Framework Agreement and which results in "contracts for life" (Mercadona, 2010).

These firms share Mercadona's TQM-based management philosophy, and their relationship with Mercadona is long-term and indefinite, with a willingness to undertake activities jointly. Mercadona's management is committed to the growth, development and sustainability of its "intersuppliers", and the firm dedicates substantial resources to joint research and product improvement, which help improve these firms' competitiveness and their chances of satisfying customer needs. The intersuppliers products exclusively for Mercadona and take on the "Totaler" philosophy, that is, to be prescribers of products that satisfy all the needs of the customers - the "bosses". They should offer customers recommended products that figure among Mercadona's store brands that have the highest possible quality at the lowest possible price. These suppliers must satisfy some requirements in order to obtain the "intersuppliers" status. Firstly, the company owners must have "passion" for what they are doing, that is, they have to be proactive, innovative and completely involved in their business. They must also have the economic resources necessary to carry out their business goals as well as the management ability to develop them. Secondly Mercadona sought companies with stability on the stock market, as they transmit security to the relationship. Furthermore, they must be companies that have an open-minded attitude with respect to information and indicators coming from customers and the market in order to provide solutions to meet customer's demands. The candidates must also be willing to introduce the TQM model in their organizations and seek to satisfy all of its components, which include the study and modification of every aspect with the aim of improvement, guaranteeing nutritional and environmental safety, and willingness to be audited by Mercadona to verify the degree to which they fulfill the model's requirements. Finally, Mercadona requires the exclusive manufacturing of some products as a result of the relationship of mutual trust and cooperation between both companies.

The process by which a firm becomes one of Mercadona's "intersuppliers" or "integrated suppliers", which is one of the most innovative and original aspects that Mercadona has contributed to the TQM model, is long and complex, and consists of three stages. In the preliminary or approach stage, candidate firms must occupy a position of leadership and have a consolidated and reliable production system. In the second stage, the firm and Mercadona establish a relationship where they share all information-a true partnership. In the third stage, the supplier must produce in response to customer needs and starting from their expectations and demands. This is why Mercadona shares the information it obtains from its customers through various mechanisms with its suppliers, and works with them in projects to produce new products.

This is when the relationship fits perfectly with Mercadona's management philosophy, which is to try to become a "prescriber" of products for all its customer's shopping. For this, Mercadona must use the information obtained to inform its "intersuppliers" of customer needs, and the two firms must jointly develop products and services, apply the TQM model in a coordinated way, and use the value-effort model to measure each other's value generation. 


\subsection{Orientation towards society}

Analyzing the impact of the firm's actions on its social environment is also a defining aspect of firms with a management model based on total quality. In fact, it is a principle of TQM that, by contributing to the development of society, Mercadona would increase its own potential for development. The company attempted to detect what society needed through its communication with customers, as well as through business organizations and municipalities (Ton and Harrow, 2010). Mercadona's social strategy runs a large number of initiatives seeking social advances in various aspects: education and research; improvement and care for the natural environment; programs to help people with health problems and disadvantaged people; revitalization of trade in urban areas; participation in sectorial associations of commercial distribution; and finally, creation of wealth and jobs in the Spanish agro-food sector.

In education, Mercadona participates in initiatives linking university studies with business activity, fundamentally in the region of Valencia, and runs research programs in the agro-food field. To care for and improve the natural environment, the firm has adopted the principle of behaving responsibly toward the environment incorporating "environmental productivity" (Ton and Harrow, 2010). The firm runs waste recycling programs, studies waste treatment, implements measures and global solutions aiming to minimize the environmental impact of its activities, seeks mechanisms that achieve maximum energy efficiency, and optimizes merchandise distribution systems both nationally and in the cities ${ }^{7}$.

With regard to Mercadona's assistance for social groups with health problems and disadvantaged people, the supermarket chain sells special gluten-free products for customers with celiac disease, and sugar-free products for diabetics, thereby helping these groups with their shopping. The firm has also signed agreements with public institutions to promote joint measures aimed at helping victims of domestic violence to find employment, and professional and social training programs for young people with social problems and difficulty entering the labor market. Mercadona has also contributed visibly to revitalizing and re-energizing local city-centre trade, for this, the firm has restored and re-launched traditional Spanish indoor markets situated in the city centre, putting a supermarket inside.

Mercadona participates in sectorial and wealth-generating associations such as the Spanish Association of Supermarkets (ASEDAS) and the Spanish Association of Commercial Codification (AECOC), which work in favor of the development of the commercial distribution sector. With regard to wealth creation, it is interesting to note the

\footnotetext{
${ }^{7}$ Mercadona has a commitment with sutainable Transport under the principle of "Transport more with fewer resources". The company is using a combination of trucks, trains and ships to reduce the environmental impact. With regard to the logistics system in cities, the firm has implemented the Urban Merchandise Transport system (TUM) with Silent Nightime unloading in more than 407 stores. In this system, products are unloaded to supermarkets in the early morning from large, silent articulated lorries. This system cuts noise pollution, traffic congestion and the negative impact on the environment: the reduction in $\mathrm{CO}_{2}$ emissions is equivalent to 30,000 cars. Meradona invested 23 in the environment in 2010. In addition to that Mercadona was recognized by the European Union as an example of a company that fosters good environmental practices (Mercadona, 2010).
} 
retailer's important and growing contribution to Spain's GDP8 its leadership in the generation of stable employment in Spain, and its substantial investment in the Spanish agro-food industry.

Finally, the most notable of Mercadona's characteristics is that the company is not content with just implementing initiatives that show its commitment and responsibility to society. The firm also strives to measure the impact of these policies. With this purpose, in 2002 Mercadona voluntarily commissioned an ethics audit from an independent association. This resulted in a highly satisfactory assessment of the firm's compliance with the requisite ethical standards, and according to the management this should serve as reference for the development of the firm's corporate social responsibility policy ${ }^{9}$. Moreover, in another external study from an independent, international organism - the report on corporate reputation that the Reputation Institute publishes annually-Mercadona has the fourth best corporate reputation in the world, behind only Lego, Ikea and Barilla ${ }^{10}$ (Reputation Institute, 2007).

\subsection{Orientation towards capital}

The company's TQM model also has repercussions at the level of economic-financial results and value creation for its owners. Mercadona is a family firm that is not listed on the Stock Exchange. Its stock ownership is highly concentrated: the majority of the ownership and control is in the hands of the company's President, Juan Roig, and his family.

The President argues that under the TQM model it is also "fair" to satisfy the needs of the company's final component, the capital, in other words, those people and organizations that invest their money in the firm and hence provide economic resources. This means that Mercadona also has a clear orientation toward profit maximization, as a means of satisfying its stockholders' needs and desires (Caparrós \& Biot, 2006). The company's management model has the aim of offering its stockholders various advantages that they will regard as valuable, such as profitability, stability, security and minimum risk in their investment. Mercadona was focused on long -term profitability, continuous improvement in productivity and reinvestment of profits to increase equity. In line with this position, the firm's economic performance can be classed as spectacular. The company's net profits have increased more than 14-fold from 1997 to 2007, reaching €336m in 2007. Figure 6 in the next page shows the evolution in both gross and net profits after the company introduced its TQM model.

\footnotetext{
${ }^{8}$ Mercadona's contribution to Spanish GDP was $€ 960 \mathrm{~m}$ in $2002, € 1,233 \mathrm{~m}$ in $2003, € 1,471 \mathrm{~m}$ in 2004, $€ 1,756 \mathrm{~m}$ in $2005, € 2,140 \mathrm{~m}$ in $2006, € 2,516 \mathrm{~m}$ in $2007, € 2,681 \mathrm{~m}$ in $2008, € 2,662$ in 2009 and $€ 3,059 \mathrm{~m}$ in 2010,(Mercadona, 2010).

${ }^{9}$ The ethics audit, commissioned from the Spanish Foundation for Business Ethics (ETNOR), aimed to provide a reliable picture of the perception that the five components have about the firm. ETNOR carried out 2,000 contacts consisting of personal interviews and telephone questionnaires. Respondents were asked about how they felt they had been treated in relation to the following aspects: integrity, credibility, fairness, dialog, transparency, dignity, legality, corporate citizenship, environment, and responsibility. Mercadona was awarded 4.31 points out of 5 for its ethical standards. The firm committed itself to repeat the audit every three years, ETNOR (2003), Mercadona (2003-2007).

${ }^{10}$ In 2010 the company held the tenth place in the Reputation Institute ranking and it has become one of Spain's two leading private companies in terms of its reputation, according to an annual study conducted by KPMG (Mercadona, 2010).
} 
With regard to the distribution of its profits, the firm re-invests a large part of them, thereby favoring firm growth. This has allowed the firm to grow organically and carry out a spectacular expansion strategy, opening new supermarkets, warehouses and logistics centers throughout the whole country in recent years. Figure 5 shows the evolution in the firm's equity and investments. This is the result of a careful policy of profit distribution allowing the firm to strengthen and increase its equity and multiply the investments that enable growth and expansion. This has ensured that the TQM model has had positive and multiplicative effects.

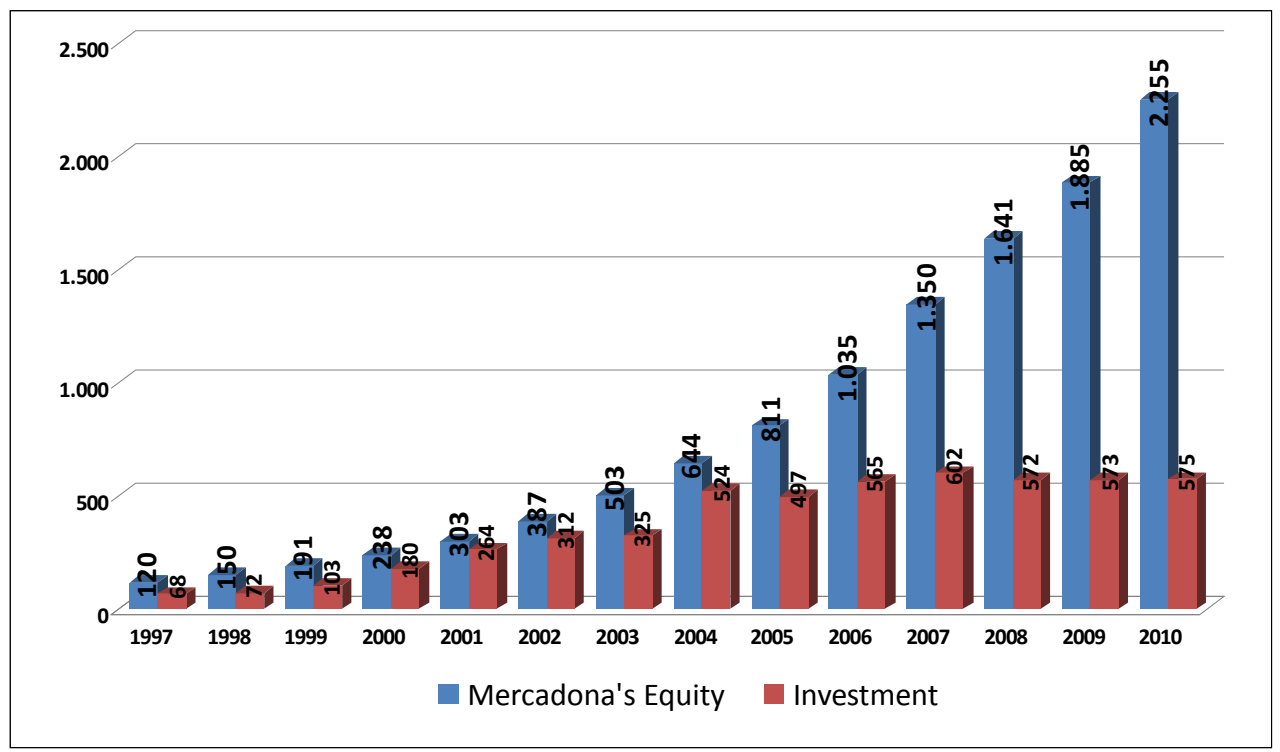

Fig. 5. Evolution in Mercadona's equity and investments $(€ \mathrm{~m})$

Source: The Authors, based on Mercadona Annual Reports.

The evolution in the firm's main economic indicators clearly reflects, in the words of the management, the "idealness" of the Total Quality Management model (Caparrós \& Biot, 2006), and is the result of satisfying the other four components of the model: customers, employees, suppliers, and society. Continuing the current policy, as well as improving and consolidating the TQM model, should ensure the future viability of the project, confirm the trend in improved results, and increase the value of stockholders' capital.

\section{Facing the economic crisis: The strength of Mercadona's total quality management model}

The global economic crisis, which began in September 2007 with the bursting of the U.S. property bubble has seriously affected Spain by late 2008 (Ton and Harrow, 2010). During the second half of 2008 the effects of the Global Economic crisis started to be clearly noticed in Spain. The crisis has been characterized in Spain by a high rate of unemployment, significantly above the average European rate and an important credit restriction in capital 
markets (Alonso and Furio, 2010). Actually, Spain has recorded the highest rate of unemployment in the European Union lately. This situation logically had a considerable impact in consumers' buying decision who tried to adjust as much as possible their budgets as well as reduced the number of transactions.

Facing such a situation, Mercadona's top management team was aware from the data from the reports tracking market's evolution that the company was starting to loss customers in its stores. According to its 2008 reports, the clients were starting to consider Mercadona "an expensive supermarket". This situation was translated into a significant reduction in Mercadona's profit that broke with an increasing trend from previous years (Figure 6)

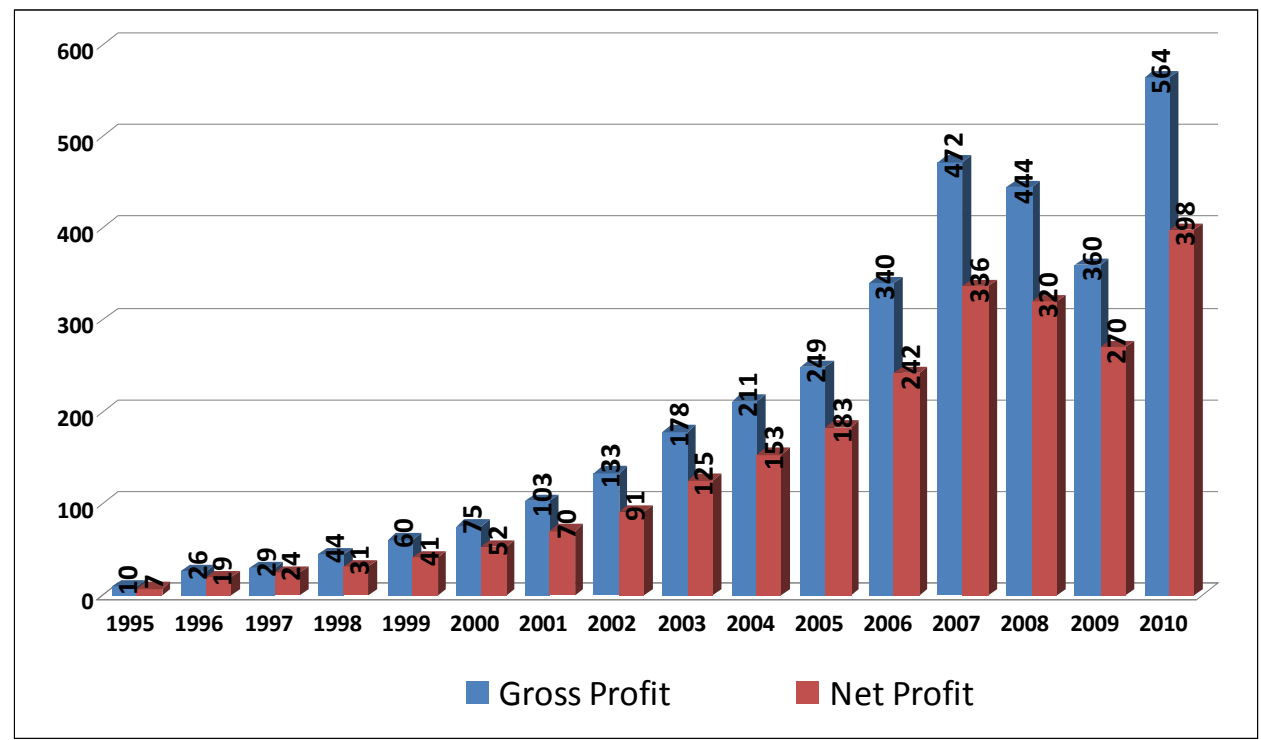

Fig. 6. Evolution in Mercadona's gross/net profits 1995-2006 (€m)

Source: The Authors, based on Mercadona Annual Reports.

Mercadona's Top Management team started to be really worried with business and profits evolution and tendency and it decided to undertake a deep strategic reflection about its business. As a result the company was able to justify the situation based in internal and external causes. Externally, the company concluded that the situation characterized by an extremely high unemployment rate and clients' difficulty to access credit, economic crisis was significantly damaging Mercadona's business. Internally, Mercadona's president noted "Based on plenty times and the belief that growth was going to last forever we had been sleepy" (Mercadona, 2008).

Taking into account this starting point, Mercadona decided to provide an answer and face that situation putting "The boss" once again at the heart of every decision the company made. Mercadona decided it had to lower its prices. Firstly, the company decided to perform a full review of the assortment of 8,000 references that it was offering to its "bosses" in the stores. Such analysis was made with the clear aim of provide an answer in line with "reduce prices" and using two criteria: 
1. Did the products and commercial formats satisfy customers' needs? (Need)

2. What is the level of product turnover? (Rotation)

The analysis allowed the company to realize that it had product in the shelves which were not adding value to its customers. In 2008 Mercadona sold, for example, 72 types of milk, 112 types of juice, 100 types of coffee, carrots of every shape and size, and several types of tomato sauce. The products in some categories, such as coffee, varied only slightly (Ton and Harrow, 2010). So the company decided working to do away with anything that does not add value to the process, that raises product prices and that affects directly the grocery budgets of the customers, who "are only willing to pay for real improvements" (Mercadona, 2010)

The review was made taking into account two basic assumptions, first to eliminate everything that was not adding value to "the bosses" and, second, trying to discover everything that improving quality and product safety was, in fact, adding value. As a result of the analysis, the company was conscious that it had numerous products and commercial formats in basic and highly consumed product like milk, fruit juices, coffee and tomato sauces as well as in cleaning and hygiene products that were not satisfying customers' needs and consequently they are not adding value to the clients.

According to the analysis performed, the company decided to eliminate 800 products of the assortment, being half of them "recommended" Mercadona's branded products. The products eliminated were shown to the media in the conference press when the president presented Mercadona's 2008 results (Figure 7).

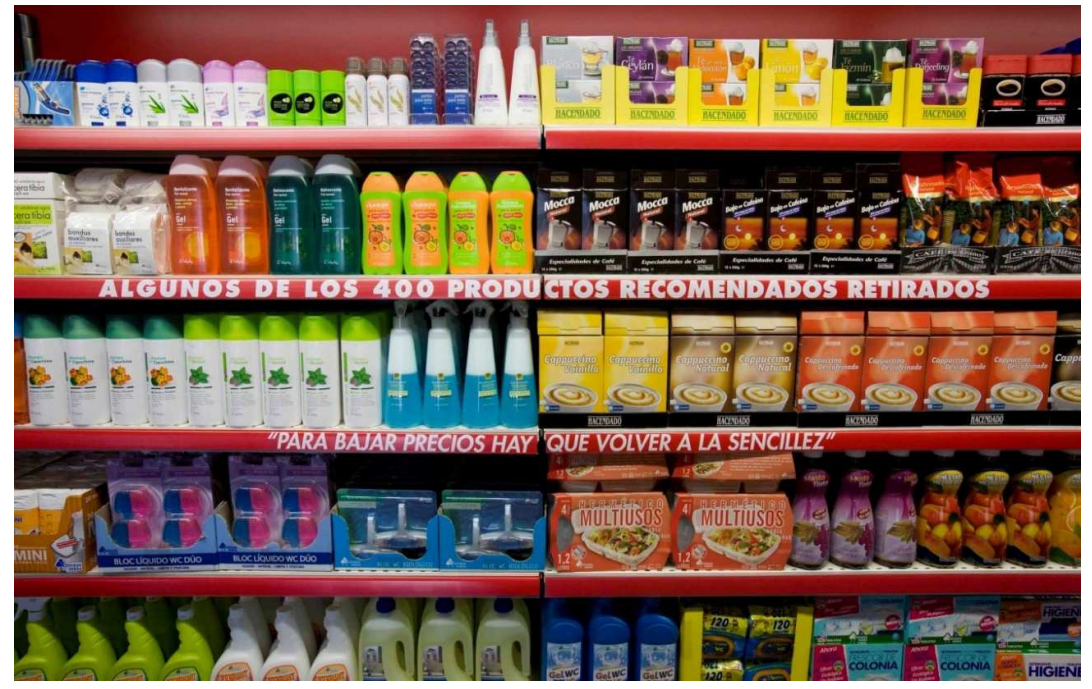

Fig. 7. Some of the references eliminated by Mercadona's shelves

Source: Mercadona Annual Report (2008)

Once the analysis had been made, the company decided to realign its strategy again with TQM model and under one of the basic assumption of its competitive strategy, "Reduce Prices". Mercadona's top management team focused the strategic review as a return to "Total Quality Management model" and to the core activity of the firm "to be storekeepers". 
The idea was to satisfy clients demands and needs with "a cart will all the needed products with the best quality and with the lowest price, prescribing them the best relationship between quality and price for each product and giving them the option of being right in their shopping decisions". Mercadona named that cart "the shopping cart menu" (Mercadona, 2008:7).

The notion of "Shopping cart menu", as a complete assortment of products that allows the company to satisfy all the clients' needs is the answer from a basic commercial learning made by Mercadona. The client was not worried by the individual price of each one of the different products that were in the cart on the contrary he was worried for the final price of the whole cart (Figure 8). Given that basic assumption, if the company is able to reduce the price of the whole shopping cart, it will be perceived as the supermarket chain cheaper in the market, which, in an environment characterized by the economic crisis will attract an increasing number of clients.

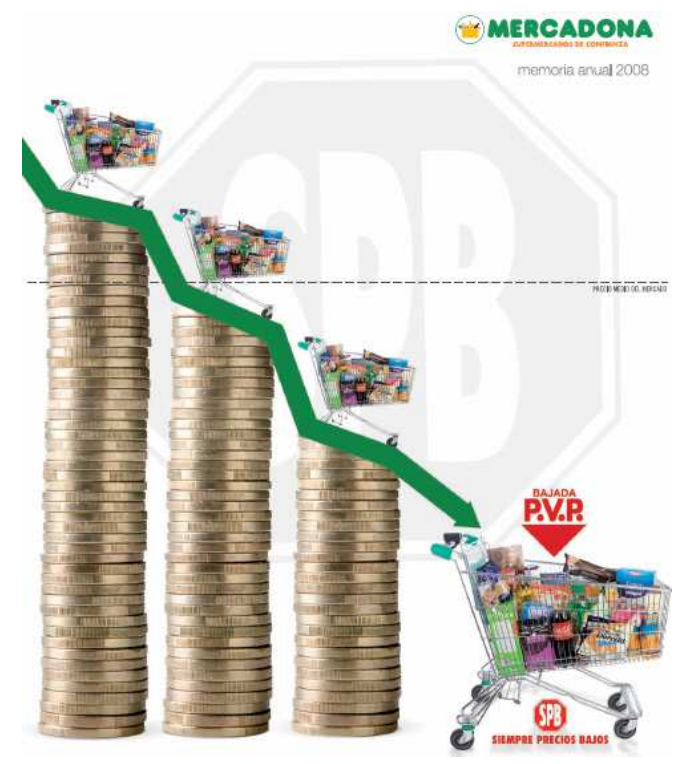

Fig. 8. Mercadona's 2008 Annual Report Cover

Source: www.mercadona.es

So, Mercadona designed in 2008 a complete program of actions oriented to reduce the price of the shopping cart for its clients. The program considered a full review of both Mercadonas' products and business processes with the aim of eliminate all the elements that were adding cost without adding value to clients. After the businesses process review and the subsequent implementation of more than 600 hundred innovative initiatives the company saved more than 500 million euro cooperating with its "integrated suppliers". Between the most outstanding initiatives of cost reduction it was a sound action the elimination of trays, fixed weight and plastic in the packing of fruit and selling them loose implied a saving of 0,35 euro per Kilo which along 2009 was translated in an annual total save of 175 million euro (Mercadona, 2009). 
As a result of this program and under the principle of "Back to basics" (Volver a la sencillez), Mercadona started to lower the price of the products effecting directly the reduction in the price of the raw materials, going to an efficient assortment and reducing firm profit but increasing the volume of products sold. The idea was that through the lower cost in the businesses processes the company was going to have lower prices and higher sales (Ton and Harrow, 2010). In this context the company is not defining economic objectives but quantity or volume of products sold objectives. In order to do this, it has defined a new measure from the kilo and liter sold the "Kiliters" according to which it has defined its objectives.

The result of this strategy has been a reduction of $10 \%$ in the prices in Mercadona's supermarkets along 2009 (Mercadona, 2009) and a 14\% drop in prices since 2009 (Mercadona, 2010). According to Mercadona's estimates it has meant a monthly household average spending reduction of 60 euro and of 720 euro per year for its customers (Mercadona, 2009). The search for excellence in each and every one of Mercadona's processes allowed the company to offer its customers savings in excess of 700 million euro in 2010 stemming from a $4 \%$ price reduction in the "Shopping Cart Menu". If the company adds the 1,500 euro in savings in 2009 and which continued to pass on in 2010 the total savings was 2,200 million euro in 2010. None of this would have been possible without the proven dedication of the company's integrated suppliers and the commitment of its employees (Mercadona, 2010).

\section{Conclusion}

This chapter shows that the total quality management approach has oriented Mercadona's management model and helped the firm to achieve spectacular economic results and a profitable and outstanding growth (from 1995 to 2007) as well as face successfully a challenging situation of economic crisis (from 2008 to 2011). The key aspect of the model is the high consideration awarded to its five components, as well as the orientation of the whole company toward satisfying their needs and expectations.

The chapter shows that Mercadona's top management decision to orient the company's entire management towards satisfying customer needs was correct. But the chapter also shows that the company cannot achieve an optimal management of customer needs without also satisfying the needs of the firm's other stakeholders. Thus, Mercadona's human resource management implements initiatives that strengthen employees' commitment to and involvement in the firm's project. The firm has installed a policy of cooperation, trust and mutual collaboration in its supplier management, which ensures that the products on the supermarket shelves match customers' requirements and specifications more closely and could be adapted in case the economic situation required that. Nor does the firm ignore the social and economic context in which it operates. This can be seen both quantitatively in terms of the creation of wealth and value, and qualitatively in terms of its ethical and environmental commitment with Spanish society and citizens. Finally, with regard to the capital, the economic results of the model are spectacular and have catapulted the company to a position of leadership among Spanish supermarket chains and a competitive advantage that its rivals will find difficult to match. In fact its competitors are currently reacting by imitating its management model and copying some of its initiatives and policies.

So, Mercadona offers the lowest prices in Spain, and its operational performance exceeds that of comparable Spanish and foreign chains. In 2008, Mercadona's sales per square foot was $60 \%$ 
higher than that of France's giant Carrefour, and more than twice that of an average U.S. Supermarket. Sales per employee were 18\% higher than that of other Spanish supermarkets that disclosed financial information that year and more than 50\% higher than U.S. supermarkets (Hanna, 2008). The difference is Mercadona's Total Quality management model (Table 1), as Mercadona's president noted is "the reason for our success" (Ton and Harrow, 2010:2).

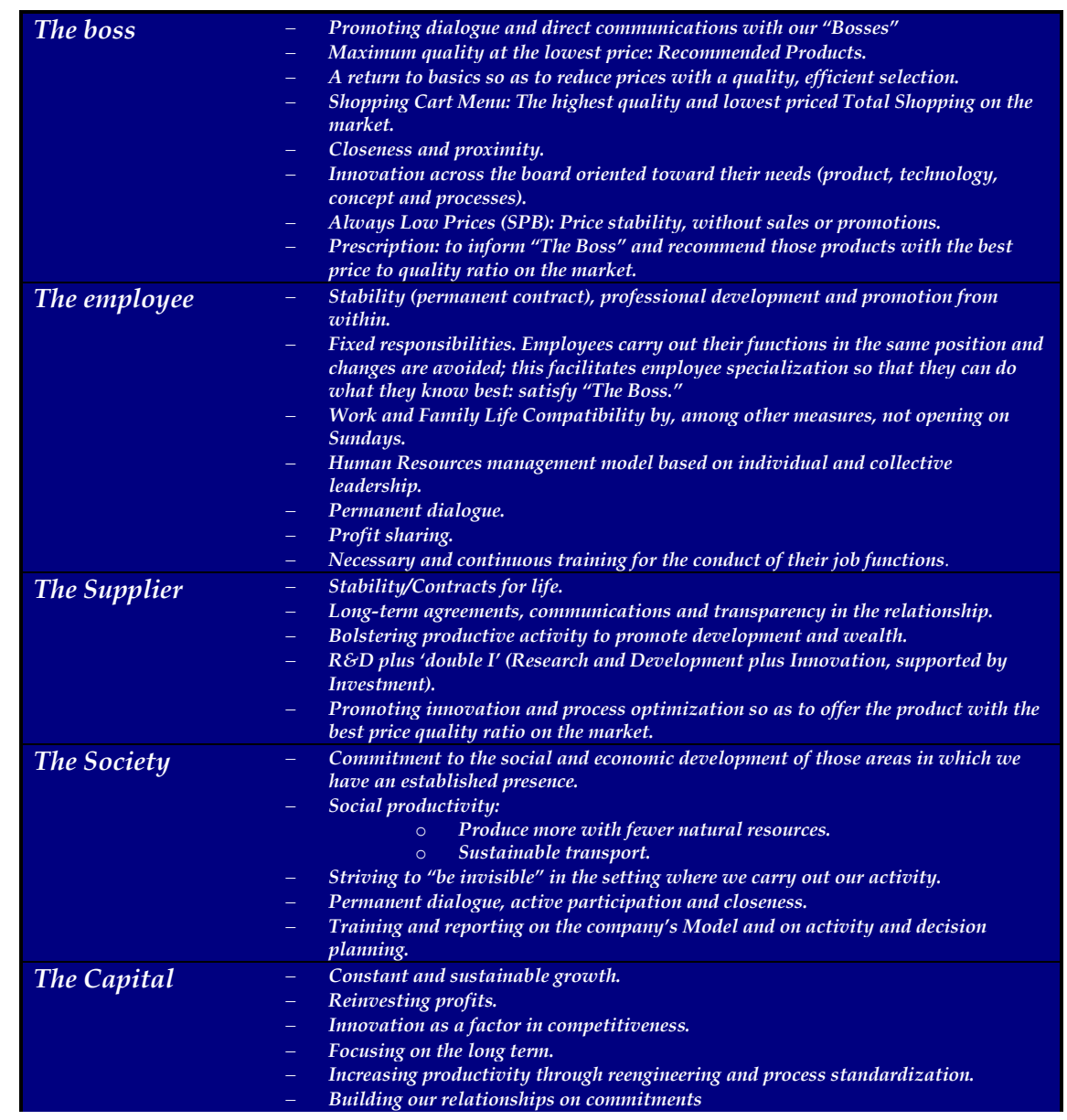

Table 1. Mercadona's Total Quality Management Model Source: 2010 Mercadona's Annual Report

In any case, the above describes an outstanding example of the successful application of the TQM model in the highly competitive, mature commercial distribution sector. Reading this chapter should encourage managers to consider the implementation of this model in other sectors of activity, although clearly, and as the literature observes, firms will need to make certain adjustments to the actions and policies depending on their particular industry (Wicks, 2001) and geographical area (Lagrosen, 2002). Proof of the feasibility of introducing this model in other industries and sectors comes from the fact that the model has spread 
sucessfully to some of Mercadona's intersuppliers or "integrated suppliers". Indeed, some of these have achieved even better results and growth rates than the supermarket chain itself (Blanco and Gutierrez, 2010).

Finally, Mercadona's Total Quality management model, thanks both to its feedback mechanisms and its great capacity to adapt to environmental and dramatic economic changes, is guaranteeing the future of the firm, even in a challenging economic situation like the one that Mercadona is currently facing in a country with an unemployment above $20 \%$ and a significant difficult to access credit. In spite of the recession, the company has managed to prove that it can "move forward and grow in difficult times" increasing the turnover, creating jobs and boosting company's productivity (Mercadona, 2010). The strength of Total Quality Management Model and the tight links that create between firm's stakeholders has allowed the firm to effectively and efficiently respond to the lost of clients caused by the economic crisis in 2008 transforming the crisis from a threat to firm survival to an opportunity to increase its market share and consolidate its competitive advantage over competitors.

\section{Acknowledgement}

This chapter has been supported by Project ECO2009-10358 of Spanish Ministry of Science and Innovation (Spain) and Catedra Iberdrola for Research in Business Management and Organization.

\section{References}

Alonso, M.; Furio, E. (2010). La economía española del crecimiento a la crisis pasando por la burbuja inmobiliaria, Cahiers de civilisation espagnole contemporaine, Vol 6, Available from http:/ / ccec.revues.org/index3212.html

Blanco, M.; Gutierrez, S. (2010). Application of the Total Quality Management Approach in a Spanish Retailer: The Case of Mercadona. Total Quality Management and Business Excellence, Vol.21, No.12, (December 2010), pp.1365 - 1381

Caparrós, A. \& Biot, R. (2006). $15 x$ 15, quince días con quince empresarios líderes. Fundación para la Comunidad Valenciana - Escuela de Dirección de Empresas del Mediterráneo (EDEM), Valencia, España

Deloitte (2007). Global Powers of Retailing 2006, New York, USA

ÉTNOR (2003). Informe de Auditoría Etica. Fundación para la ética de los negocios y las administraciones, Madrid, España

Hanna, J. (2010). How Mercadona Fixes Retail's “Last 10 Yards" Problem, ResearchEIdeas, Harvard Business School Working Knowledge, Cambridge, MA.

INE (2011). Instituto Nacional de Estadística (National Statistics Institute). Data available from http://www.ine.es/

Lagrosen, S. (2001). Strengthening the weakest link of TQM - from customer focus to customer understanding. The TQM Magazine, Vol.13, No. 5, pp. 348-354.

Mercadona. (1999-2010). Mercadona's Annual Reports. Tavernes Blanques, Valencia, España

Navarro, R. (2005). Los nuevos burgueses valencianos., La esfera de los libros, Valencia, España

Reputation Institute (2007). Global Rep. Track Pulse 2007. Reputation Institute, New York, USA

Ton, Z.; Harrow, S. (2010). Mercadona. Harvard Business School Cases. 9-610-089. Cambridge, MA, USA

Wicks, A.C. (2001). The Value Dynamics of Total Quality Management: Ethics and the Foundations of TQM. Business Ethics Quarterly, Vol.11, No.3, pp. 501-536. 


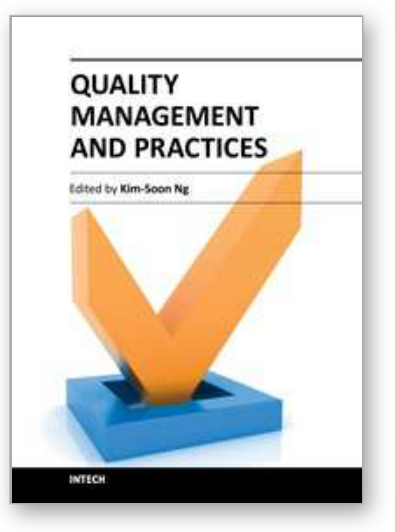

\author{
Quality Management and Practices \\ Edited by Dr. Kim-Soon Ng
}

ISBN 978-953-51-0550-3

Hard cover, 254 pages

Publisher InTech

Published online 27, April, 2012

Published in print edition April, 2012

This book is comprised of a collection of reviews and research works from international professionals from various parts of the world. A practical approach to quality management provides the reader with the understanding of basic to total quality practices in organizations, reflecting a systematic coverage of topics. Its main focus is on quality management practices in organization and dealing with specific total quality practices to quality management systems. It is intended for use as a reference at the universities, colleges, corporate organizations, and for individuals who want to know more about total quality practices. The works in this book will be a helpful and useful guide to practitioners seeking to understand and use the appropriate approaches to implement total quality.

\title{
How to reference
}

In order to correctly reference this scholarly work, feel free to copy and paste the following:

Miguel Blanco Callejo (2012). Using Total Quality Management Model to Face the Economic Crisis: The Case of Mercadona, Quality Management and Practices, Dr. Kim-Soon Ng (Ed.), ISBN: 978-953-51-0550-3, InTech, Available from: http://www.intechopen.com/books/quality-management-and-practices/using-total-qualitymanagement-to-face-the-crisis-the-case-of-mercadona

\section{INTECH}

open science | open minds

\section{InTech Europe}

University Campus STeP Ri

Slavka Krautzeka 83/A

51000 Rijeka, Croatia

Phone: +385 (51) 770447

Fax: +385 (51) 686166

www.intechopen.com

\section{InTech China}

Unit 405, Office Block, Hotel Equatorial Shanghai

No.65, Yan An Road (West), Shanghai, 200040, China

中国上海市延安西路65号上海国际贵都大饭店办公楼 405 单元

Phone: +86-21-62489820

Fax: +86-21-62489821 
(C) 2012 The Author(s). Licensee IntechOpen. This is an open access article distributed under the terms of the Creative Commons Attribution 3.0 License, which permits unrestricted use, distribution, and reproduction in any medium, provided the original work is properly cited. 